\title{
Mon Bête Noir (My Pet Peeve)
}

\author{
Michael E. Mullins
}

Published online: 2 April 2011

(C) American College of Medical Toxicology 2011

Keywords Torsades des pointes

In 1966, Francois Dessertenne, writing in French about a particular dysrhythmia, coined a familiar term which is usually translated as "twisting of the points" [1]. For fourand-a-half decades, Anglophones have generally written the term with singular and plural words used together incorrectly. The correct form has been debated and discussed from time to time while the error persists $[2,3]$. Rarely do authors write this correctly [4].

The most common version appears to be "torsades de pointes". Other variations, such as "torsade de pointes" and "torsade de pointe", seem less frequent. Dessertenne may have contributed to the confusion by using different versions in different articles.

The term includes two nouns which usually and correctly appear in their plural forms. Most authors agree that the "points" (English) refer to the tips of the QRS complex in plural, so "pointes" must be correct. A minority view holds that the axis of rotation is the point, but this belies the preposition "of" and would require "on", "around", or "about" instead. Only torsades en pointe would describe this interpretation.

M. E. Mullins $(\bowtie)$

Division of Emergency Medicine,

Washington University School of Medicine,

Campus Box 8072, 660 S. Euclid Avenue,

St. Louis, MO 63110, USA

e-mail: mullinsm@wusm.wustl.edu
The first noun referring to "twisting" usually appears in plural form but often appears in the singular form also. Some argue that the term can be either singular or plural, depending upon how many cycles of rotation are observed. However, the term describes a pattern which can only be recognized when it repeats. Also, Dessertenne used the definite article "les" (plural "the") in his original description [1]. The most correct form of the first noun must be "torsades", with a silent "s" at the end of the word.

The connecting word "des" is the smallest and the most frequently written incorrectly. "Des" translates either as "of the" or as the plural indefinite article "some". In either use, "des" necessarily precedes a plural noun. Hence all three words should be plural.

Authors with savoir-faire should write "torsades des pointes" while noting that each plural "s" is silent.

Example 1: torsades de pointes (incorrect)

Example 2: torsade de pointes (incorrect)

Example 3: torsade de pointe (incorrect)

Example 4: torsades des pointes (correct)

\section{References}

1. Dessertenne F (1966) La tachycardie ventriculaire a deux foyers opposes variables. [Ventricular tachycardia with 2 variable opposing foci]. Arch Mal Coeur Vaiss 59:263-272

2. Fontaine G (1992) A new look at torsades de pointes. Ann NY Acad Sci 644:157-177. doi:10.1111/j.1749-6632.1992.tb31009.x

3. Moise NS (1999) As Americans, we should get this right. Circulation 100:1462

4. Parrish C, Wooster WE, Braen GR, Robertson HD (1982) Les torsades des pointes. Ann Emerg Med 11:143-146 